\title{
Liberal trade laws linked to obesity
}

$\mathrm{T}$ he looser the free market, the thicker a nation's waistlines. At least, that appears to be the case, according to a recent study linking market deregulation to higher rates of obesity.

Deregulation refers to the degree of freedom - from taxation, trade restrictions and other forms of government intervention - businesses have to operate in a country. The study, published in the Bulletin of the World Health Organization, found that obesity rates are rising more rapidly in countries most welcoming of foreign investment.

"Though it has been suspected that trade deregulation can lead to an increase in the consumption of unhealthy foods, nobody had shown it empirically," says Roberto De Vogli, lead author and associate professor of epidemiology at the University of California Davis.

To gauge the degree of market deregulation, the researchers used a tool called the index of economic freedom. Countries with stricter trade rules - perhaps to protect local farmers, for instance - still had rising levels of obesity, but the rates of increase were lower than in nations with fewer economic restrictions.

Though researchers aren't sure of the reason, one theory is that freer markets favour large, multinational corporations and fast food chains over local food providers, who tend to sell healthier fare. Food that travels across oceans also requires longer shelf lives, so these products tend to be highly processed.

"Over the past 20 years, there has been a huge expansion of multinational food companies and fast food chains throughout the world," says Dr. Frank $\mathrm{Hu}$, professor of nutrition and epidemiology at the Harvard School of Public Health in Boston, Massachusetts. "For example, in China, there was only one McDonald's restaurant in 1990, but it has now grown to more than 1000 in two decades."

Globalization is not all bad, says $\mathrm{Hu}$. It has increased the variety of foods and beverages in many countries and can result in lower prices for consumers. The challenge - and it is a formidable one, stresses $\mathrm{Hu}-$ is to

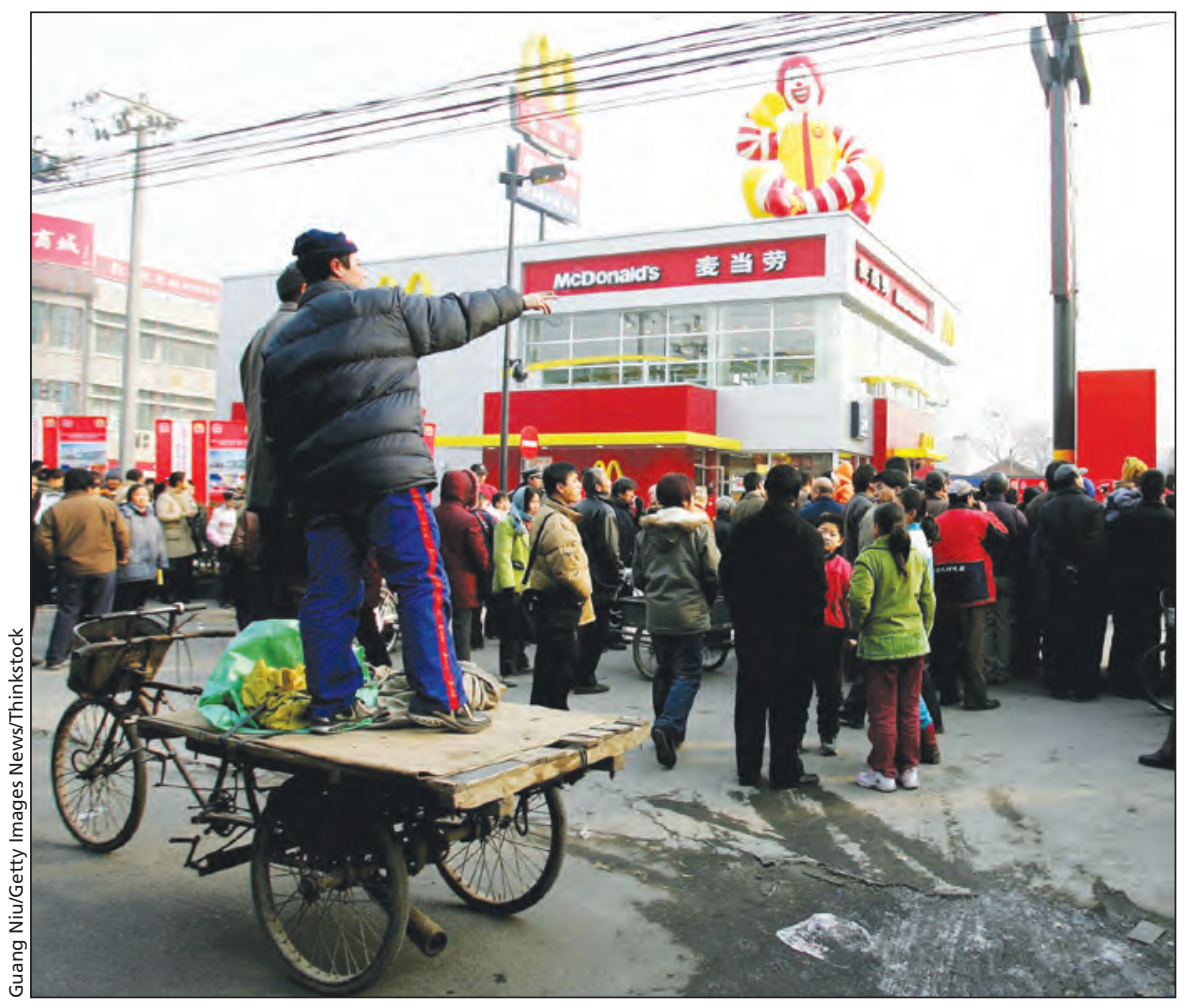

Globalization has led to a rapid expansion of fast food restaurants in many countries, such as China, over the past two decades.

harness the benefits of globalization while minimizing the negative consequences. To do that, governments must recognize that changing trade policies is not only an economic issue, but also a public health issue.

"Many governments are pretty short-sighted," says Hu. "They see businesses growing and generating revenues for the country, but they don't see the long-term consequences of diabetes and other obesity-related diseases, and these enormous costs can easily offset and surpass the economic benefits from increasing business and trade."

There is very little, if any, involvement of public health experts in the development of trade policies, notes De Vogli. To address the global obesity epidemic, however, governments may have to reconsider just how free their markets should be.

"This is where government regulation comes to the fore," says De Vogli. "We can't expect that fast food companies and other businesses are going to cooperate with us to fight obesity. We need to force them to do it."
Of course, it is not only the deregulation of international trade laws that contributes to obesity, notes Marion Nestle, a professor in the Department of Nutrition, Food Studies and Public Health at New York University in New York City. In the United States, for example, various forms of domestic deregulation have also been linked to increased rates of obesity.

In the 1970s, regulatory changes prompted US farmers to grow as many crops as possible, says Nestle, and that led to an increase in the number of daily calories consumed per capita. The food industry also became hypercompetitive, pumping out more and more product, because of a shareholder value movement that pressured companies to maximize returns to investors. Deregulation of marketing directly to children has also played a role.

"All of these fostered the rapid growth of fast food companies and larger portions," Nestle writes in an email. "Hence: obesity." - Roger Collier, CMAJ 